\title{
A multiple case study of small free software businesses as social entrepreneurships
}

\author{
Ann Barcomb \\ Friedrich-Alexander-University Erlangen-Nürnberg \\ Martenstraße 3 \\ 91058 Erlangen, Germany \\ ann@barcomb.org
}

\begin{abstract}
Free/libre and open source software are frequently described as a single community or movement. The difference between free software and open source ideology may influence founders, resulting in different types of companies being created. Specifically, the relationship between free/libre software ideology and social entrepreneurships is investigated. This paper presents seven case studies of businesses, five of which were founded by people who identify with the free/libre software movement. The result is a theory that small businesses founded by free/libre software advocates have three characteristics of social entrepreneurships. First, social benefit is prioritized over wealth creation. Second, the business's social mission is not incidental but is furthered through its for-profit activities, rather than supported by the company's profits. Third, the company's success is defined in part by the success of its social mission Free/libre software entrepreneurs who recognize their activities as social entrepreneurships can benefit from the existing literature on the unique challenges faced by socially-oriented businesses.
\end{abstract}

\section{Categories and Subject Descriptors}

K.4.0 [Computers and Society]: [General]; K.4.1 [Computers and Society]: Public Policy Issues-Ethics; K.6.0 [Management of Computing and Information Systems]: General-Economics; K.7.4 [The Computing Profession]: Professional Ethics-Codes of Ethics

\section{General Terms}

Human Factors

\section{Keywords}

free software, open source software, public good, small business, social entrepreneurship, social ventures

\section{INTRODUCTION}

People who are part of the free/libre software (FOSS) movement who found businesses may express their ideals in their companies. In this paper, which is based on the author's master's thesis ${ }^{1}$, five FOSS identified companies which differ in size and viability are examined. They are compared with two companies which make use of free/libre and open source software (FLOSS) business methods but whose founders either take a pragmatic approach or identify with open source software (OSS).

In FLOSS business research, OSS business models are heavily represented and little attention is paid to companies which comply with the FOSS philosophy. There are several possible reasons why this might be the case. First, there are no large, well-known FOSS companies, and small businesses are less likely to be the focus of research, despite contributing significantly to the economy [52]. Second, it may be due to the misconception that the FOSS philosophy is hostile to business. Stallman described the FOSS view of enterprise: "The free software philosophy rejects a specific widespread business practice, but it is not against business. When businesses respect the users' freedom, we wish them success" [46]. Third, it may simply be that the FOSS/OSS distinction is of little interest outside the community. However, this difference in belief could lead to different types of businesses being created, which reflect the founders' views.

I propose to address this gap in the research by placing emphasis on the philosophical component of the FOSS movement, and examining FOSS businesses as possible social entrepreneurships. Social entrepreneurships are companies which are founded to promote the social good. They prioritize social good over profits, pursue their social aims as part of their business practices, and evaluate success in part by the extent to which the social mission is accomplished. If FOSS companies can be connected to social entrepreneurship, practitioners gain access to a pool of existing research relating to the specific challenges of balancing financial requirements and social mission.

The research question is:

1"The Sociability of Free Software" was submitted to the University of Maastricht on 1 September 2010 and is available at http://barcomb.org/papers/ barcomb-2010-sociability.pdf. This paper summarizes the substance of the thesis with additional analysis and a revision of the terminology used in the description of the research methods.
C) Ann Barcomb 2015. This is the author's version of the work. It is posted here for your personal use. Not for redistribution. The definitive version was published in Proceedings of the 11th International Symposium on Open Collaboration (OpenSym 2015), http://dx.doi.org/10.1145/2788993.2789830. 
How are companies grounded in the spirit of free/libre software comparable to social entrepreneurships?

\section{RELATED WORK}

There are two broad topics which are relevant to this research: free/libre and open source software, and social entrepreneurship. Under the heading of FLOSS I discuss definitions of free and open source software, ethics, and the motivations of individuals and companies. The social entrepreneurship section also begins with a definition, then addresses the challenges of defining social value and concludes with a discussion of the concept of success.

\subsection{Free/Libre and Open Source Software}

OSS software and FOSS have been defined by the Open Source Initiative and the Free Software Foundation, respectively. FOSS and OSS are often described as one phenomenon [31] and there is some disagreement as to whether they should be considered different movements or communities [47]. About thirty percent of developers in the early 2000s viewed the two as distinct communities. Individuals who identified with FOSS were more likely to see a difference [1]. OSS is usually viewed as a methodology, while FOSS is seen as a philosophy [31] which can be described in moral terms: "Free software' is a matter of liberty, not price" [18]. Within FOSS there are the copyleft and permissive views. Copyleft proponents believe that proprietary software should be resisted [23], while the permissive opinion is that freedom should be absolute, even if the user chooses to free-ride by incorporating FOSS into proprietary offerings [10, 37]. In a 2002 study of FLOSS developers, close to half of respondents identified with the FOSS movement [1].

The notion of what constitutes a social good can vary by individual [9], and people are inclined to view group goals as a social good when they identify with a community [19, 28]. The social nature of FLOSS is recognized [25], but FLOSS is often seen as a tool to reduce poverty (e.g., [4]), to advance education (e.g., [6]) or to avoid vendor lock-in in the public sector (e.g., [44]) rather than a social objective. From the perspective of the FOSS community, however, FOSS can be seen as a social good: "For the free software movement, non-free software is a social problem and free software is the solution" [45].

There are many reasons why people might participate in FLOSS development. Extrinsic factors include earning revenues from related products and services [21] and career advancement $[1,16,26,51]$. Intrinsic motivations include meeting a personal need $[1,21,24,42]$, identification with the community [21, 24] and idealism [1, 21, 24, 51]. Prolific developers tend to have more intrinsic motivations, while occasional contributors are motivated by need rather than altruism [42]. In a large-scale study of developers, ideological, altruistic and community motivations were represented [1]. One quarter of respondents wanted to "limit the power of large companies," one third thought "software should not be a proprietary good," and joined to "participate in the OS[S]/F[OS]S scene" while one half wanted to to "share knowledge and skills." Companies which contribute to FLOSS development are more likely to have extrinsic motivations [39] such as strategic considerations or to lower costs [53]. Firms may also support FLOSS as a public good
[3], and businesses which contribute from social motivation join more projects and are more likely to have their contributions accepted [40]. Small companies are more likely to have the same motivations as individuals [5].

\subsection{Social Entrepreneurship}

Social entrepreneurship entails "an innovative use of resources to exploit opportunities that meet a social need in a sustainable manner" [48]. It is distinguishable from other types of businesses "by the primacy and centrality of the social mission" [49] which is favored over economic wealth creation [29, $30,41,49,55]$. In a social entrepreneurship, the founding values will be visible in all aspects of the organization $[2,11]$. Although a social entrepreneurship focuses on a social need, founders may have other motivations in addition to altruism, such as personal fulfillment [29] or financial profit [41]. The ideology is nonetheless evident in the language employed by social entrepreneurs, who, compared with other company founders, are more likely to use words such as group, affiliation, obligation and helping [35].

Understanding what value is being created, and who is expected to benefit is a fundamental part of evaluating a social enterprise [33]. One criticism of the concept of social entrepreneurship is that it does not define this, but leaves it for the group or individual to determine if an activity is socially beneficial $[9,35]$. Cho argued that only the public political process can be used to identify social good [9], but Parkinson and Howorth found that many social entrepreneurs identify their activities in contrast to government policy [35]. An example is software piracy, which has been analyzed as a social entrepreneurship based on the participants' moral position on intellectual property [8].

Success should be measured by taking both social and economic performance into consideration $[33,55]$. The sustainability of the business, the extent to which it achieves its goals, and the resources available for growth are possible measures of success [43]. Measuring social change and attributing it to a particular activity are key difficulties of this mixed definition of success $[2,29,52,55]$. Mair and Marí further note that if social movements are measured exclusively in terms of success at achieving their ends, the benefits created during the period of operation are ignored [29].

From these descriptions the social entrepreneurship emerges as having the following characteristics: firstly, social benefit is prioritized over wealth creation; secondly, the company is committed to creating positive social value as part of regular business practice; and, thirdly, success is not defined in solely economic terms.

\section{METHODOLOGY}

Although data collection and data analysis are described separately, the research should be understood as an iterative process involving overlapping phases of literature review, data collection and analysis.

The research concept was revised in response to the analysis of the data and the literature, as recommended by Flyvbjerg [17]. The original question was broadly framed because the research is phenomenon-driven and there was no existing 


\begin{tabular}{lll}
\hline Code & Company & Participant \\
\hline $\mathrm{Ca}$ & Catalyst IT & Don Christie \\
$\mathrm{Co}$ & Conecta & Carlo Daffara \\
$\mathrm{Gn}$ & Gnutiken & Stian Eide \\
$\mathrm{Ob}$ & Anonymous & Anonymous \\
$\mathrm{Ot}$ & Open Source Telecom & Rich Bodo \\
$\mathrm{Ul}$ & Understanding Limited & Dave Crossland \\
$\mathrm{Wg}$ & We Go To 12 & David Grandinetti \\
\hline
\end{tabular}

Table 1: Interview Overview

\begin{tabular}{lllll}
\hline Code & Size & Status & Identity & Model \\
\hline $\mathrm{Ca}$ & medium & active & FOSS (copyleft) & FOSS \\
$\mathrm{Co}$ & small & active & unaffiliated & FOSS \\
$\mathrm{Gn}$ & micro & starting & FOSS (copyleft) & FOSS \\
$\mathrm{Ob}$ & micro & inactive & OSS & OSS \\
$\mathrm{Ot}$ & small & inactive & FOSS (copyleft) & FOSS \\
$\mathrm{Ul}$ & micro & active & FOSS (copyleft) & FOSS \\
$\mathrm{Wg}$ & micro & active & FOSS (permissive) & OSS \\
\hline
\end{tabular}

Table 2: Company Overview theory [15]. The initial question was: "Does a humanistic philosophy have an influence on the successful business model: are there parallels with social entrepreneurship, and could research on social entrepreneurship potentially be applied to free software businesses?"

\subsection{Data Collection}

Each case was centered around telephone interview(s) with a (co-)founder of a company. Potential participants were reached through posts and emails to FOSS mailing lists and forums.

Interviews were conducted in the autumn of 2009. The interviews were semi-structured and lasted approximately one hour. Participants were mailed a partial list of questions a few days before the interview. Interview sources are referred to throughout this article by the case code with the subscript $i$ and the interview number, for example $\mathrm{Gn}_{i 2}$. A summary of interview subjects and case codes can be found in Table 1.

Data triangulation was used to corroborate the primary sources [20]. The company websites, public interviews and community discussions were included in the analysis when available. These sources were primarily useful for characterizing the company's business practices and did not aid in the analysis of the founders' attitudes.

Case selection was based on polar types, where cases are selected based on contrast along important dimensions [14, 15, 54]. Table 2 gives an overview of the case selection. Points of differentiation were company size, viability/status, movement the founder identified with, whether the business model was compliant with FOSS or OSS. The research question focuses on differentiating businesses with FOSS identified founders from other companies which may share their business models.

Company size was characterized as micro $(<10)$, small $(10-$ $99)$ or medium (100-999). No larger companies were examined, both because there are no 'pure-play' FLOSS companies without proprietary offerings with more than $\$ 1$ billion (USD) in turnover $[32,34,16]$ and the founder's values are more likely to be expressed in a smaller company [52].

Business models were characterized as either OSS or FOSS. The OSS company derives the majority if its revenues through one or more of the commonly recognized open source business practices such as dual licensing or open core. By con- trast, FOSS companies "have adopted business models in which the revenue streams are not tied to proprietary software model licensing conditions" [13]. Models which incorporate proprietary software into products and sell the products as a primary source of revenue cannot be considered FOSS companies [46].

\subsection{Data Analysis}

I used the coding method described by Yin as working "from the ground up" [54]. This inductive approach is influenced by grounded theory [12] and is similar to the general inductive method described by Thomas [50]. Grounded theory is not compatible with the method of data collection described in section 3.1. Literature was also incorporated at an earlier stage to guide the development of research questions [7].

First, open coding was used to identify 55 concepts relevant to the research. Next, these were grouped into 12 categories, which were determined organically from emerging concepts [27]. For instance, the concept Using FLOSS is educational was grouped under the category direct benefits of FLOSS. Finally, the categories were unified into three overarching themes, of which two revealed new insights and were used to create the final model (success and philosophy).

A stakeholder check was performed to ensure the faithfulness of the interpretation $[27,54]$. Preliminary results were accepted by the interview subjects and other members of the FLOSS community they were shared with.

\section{RESULTS}

Two of the broader themes which were identified, philosophy and definitions of success, were relevant to the research question.

\subsection{Philosophy}

In the overarching theme of philosophy, there were four categories pertaining to beliefs and convictions. Table 3 shows these categories and whether they were observed among companies.

The first category, Direct Benefits, contained the following codes: financial advantages in using FLOSS, user empowerment, enabling freedom and the free exchange of ideas, and contributions to learning. Examples of user empowerment and learning follow.

The concept of not being locked in, of being free 
to choose who you get your service from, for instance, is now starting to be understood. . $\left(\mathrm{Gn}_{i 2}\right)$

Educational, informative and empowering. Perhaps not for everyone but for people who are inclined to dig in and figure things out it is empowering. $\left(\mathrm{Ob}_{i 1}\right)$

In the category Positive Externalities I found the codes use of FLOSS encourages sharing/collaboration in general, use of FLOSS increases transparency, FLOSS will reduce costs indirectly, and using FLOSS makes users think about freedom. The first and second codes can be seen in the following quotations.

It means, first of all free thinking, free ideas. It means collaborating. $\left(\mathrm{Ca}_{i 1}\right)$

It's influenced me - for the rest of my life, I mean, I'll be both an entrepreneur and I'll be very concerned with transparency in business and in software. And I think that it's you know, every time that Linus is on the cover of Forbes, or, you know, you can't open a Harvard business journal now without three or four open source software articles. Every time that stuff gets, those thoughts get spread, they're memes, they have lives and help people think about transparency. $\left(\mathrm{Ot}_{i 1}\right)$

In the category Social Good the following codes were observed: FLOSS promotes equality, FLOSS makes the world a better place, FLOSS is necessary, and FLOSS is innately valuable. The following quotation demonstrates the application of the final code.

By being involved in free software, ... having that kind of social contribution as well, ... I find that makes the work more meaningful. $\left(\mathrm{Ul}_{i 1}\right)$

The category Superiority of FLOSS was created from the codes FLOSS gives you control, using FLOSS increases efficiency, and FLOSS is technologically superior. Below is an illustration of the use of the codes control and technologically superior, respectively.

... you know if there's something I want to tweak, some little bug that we find, I don't want to have to wait for someone else to fix it. We have the capability to fix it. $\left(\mathrm{Wg}_{i 1}\right)$

I have quite a strong belief because I have seen that open source is capable of helping companies introducing innovation inside of their IT much faster and in times of scientific, for example, scientific software, one thing that I have found is that open source scientific software is maybe less aesthetically pleasing but significantly better than proprietary software in that area. $\left(\mathrm{Co}_{i 1}\right)$

\begin{tabular}{|c|c|c|c|c|c|c|c|}
\hline \multirow[t]{2}{*}{ Category } & \multicolumn{7}{|c|}{ Company } \\
\hline & $\mathrm{Ca}$ & Co & $\mathrm{Gn}$ & $\mathrm{Ob}$ & $\mathrm{Ot}$ & $\mathrm{Ul}$ & $\mathrm{Wg}$ \\
\hline $\begin{array}{l}\text { Direct } \\
\text { benefits }\end{array}$ & $\checkmark$ & & $\checkmark$ & $\checkmark$ & $\checkmark$ & & $\checkmark$ \\
\hline $\begin{array}{l}\text { Positive } \\
\text { externalities }\end{array}$ & $\checkmark$ & & & & $\checkmark$ & & \\
\hline Social Good & $\checkmark$ & & $\checkmark$ & & $\checkmark$ & $\checkmark$ & $\checkmark$ \\
\hline $\begin{array}{l}\text { Superiority } \\
\text { of FLOSS }\end{array}$ & $\checkmark$ & $\checkmark$ & & & $\checkmark$ & & $\checkmark$ \\
\hline
\end{tabular}

Table 3: Presence of Philosophy Categories

\subsection{Success}

The theme Success covers metrics founders use to evaluate their companies. The intermediate level of coding categorized codes according to whether they demonstrated a positive or negative view toward the concept. In Table 4, the codes under the theme Success with the positive category are shown. A list of codes follows, with illustrative quotations from the four most commonly observed codes from the positive category. customer satisfaction, free software [is the] required outcome,

It was pretty much a given that it would stay open source. We discussed that before we started the company and both of us felt very strongly... We were pretty happy about it being open source the whole way. $\left(\mathrm{Ob}_{i 1}\right)$

company growth,

I would say that a company is a failure when first of all it is not financially successful, not growing, or when you fail to make an impact in the market. $\left(\mathrm{Co}_{i 1}\right)$

the work brings personal fulfillment, there is enough money to engage in philanthropy, the company is making progress to [its] goal, the work has a purpose,

I feel that money will be a side effect [of] any other success that I have. So having things that help people make a difference. $\left(\mathrm{Wg}_{i 1}\right)$

the quality of the work is high, the company has a good reputation, staff satisfaction, and there is sufficient income to sustain the business and earn a decent living.

Well, our goal revenue-wise is to be sustainable. We don't plan or intend to get rich doing this but we would like to make a steady income from it. .. $\left(\mathrm{Gn}_{i 1}\right)$

\section{DISCUSSION}

Social entrepreneurship is characterized by the prioritization of social benefit over wealth creation, the integration of the social mission with the business objectives, and a definition of success which includes furthering social aims. 


\begin{tabular}{|c|c|c|c|c|c|c|c|}
\hline \multirow[t]{2}{*}{ Code } & \multicolumn{7}{|c|}{ Company } \\
\hline & $\mathrm{Ca}$ & $\mathrm{Co}$ & $\mathrm{Gn}$ & $\mathrm{Ob}$ & $\mathrm{Ot}$ & Ul & $\mathrm{Wg}$ \\
\hline $\begin{array}{l}\text { Customer } \\
\text { satisfaction }\end{array}$ & $\checkmark$ & $\checkmark$ & & & & & \\
\hline $\begin{array}{l}\text { Free } \\
\text { software } \\
\text { required }\end{array}$ & $\checkmark$ & & & $\checkmark$ & & $\checkmark$ & \\
\hline Growth & $\checkmark$ & $\checkmark$ & & & & $\checkmark$ & \\
\hline $\begin{array}{l}\text { Personal } \\
\text { fulfillment }\end{array}$ & & & & $\checkmark$ & & & $\checkmark$ \\
\hline Philanthropy & & & & $\checkmark$ & & & \\
\hline $\begin{array}{l}\text { Progress to } \\
\text { goal }\end{array}$ & $\checkmark$ & $\checkmark$ & & & & & \\
\hline Purpose & & & & & $\checkmark$ & $\checkmark$ & $\checkmark$ \\
\hline $\begin{array}{l}\text { Quality of } \\
\text { the work }\end{array}$ & & & & $\checkmark$ & $\checkmark$ & & \\
\hline Reputation & $\checkmark$ & $\checkmark$ & & & & & \\
\hline $\begin{array}{l}\text { Staff } \\
\text { satisfaction }\end{array}$ & & $\checkmark$ & & & & & \\
\hline $\begin{array}{l}\text { Sufficient } \\
\text { income }\end{array}$ & & & $\checkmark$ & $\checkmark$ & & $\checkmark$ & $\checkmark$ \\
\hline
\end{tabular}

Table 4: Presence of Success Codes

\subsection{Social Benefit Prioritized over Wealth Creation}

In a social entrepreneurship, promoting the public good comes before profit but not before sustainability $[29,55]$. In the interviews, a range of views were expressed about the relative importance of the financial measure of success. Table 4, showing codes related to Success, demonstrates these differences.

The primary distinction appeared to be size of the company, rather than identification with FOSS. The founders of the anonymous company, Gnutiken, Understanding Limited and We Go To 12 used words like 'sustainable' and 'decent' income (sufficient income) and had no interest in growing (growth) beyond a dozen employees.

So up until now I'm defining success is being able to earn a similar wage as I would earn as an employee and I've been successful at doing that. $\left(\mathrm{Ul}_{i 1}\right)$

In the software teams that I work with it turns out that... teams of about three or four people are optimal. And I'd love to have two, maybe three teams available. So up to ten people, twelve people. $\left(\mathrm{Wg}_{i 1}\right)$

By contrast, the interviews with Catalyst IT and Conecta showed an interest in profit and growth.

From my company perspective profitability is obviously important, as is reputation as is stability and growth. $\left(\mathrm{Ca}_{i 1}\right)$
Commitment to social objectives could be seen in the presence of the codes philanthropy and free software required. The inclusion of free software as a social good is described in section 5.2.

\subsection{Social Mission is not Incidental}

It is clear from the Philosophy codes in Table 3 that one key difference between FOSS identified founders and other entrepreneurs is the belief that FLOSS is a social good in and of itself (seen in social good) Social entrepreneurs use "caring, compassionate and moral" language [38] when speaking about their companies and reference concepts such as helping, affiliations and necessity [35]. The following quotations, coded as making the world a better place (in the category social good) demonstrate how company founders can view their FOSS work as socially valuable.

It's my main concern mostly because it's the most underrated way of saving the world, in my opinion. I think free software is so important that everyone really should use it. $\left(\mathrm{Gn}_{i 1}\right)$

And I would consider other companies which are not producing free software no matter how much revenue they're making or the functional quality of the software that they've developed, I'm not sure I'd consider them successful, because they are proprietary. $\left(\mathrm{Ul}_{i 1}\right)$

Viewing FOSS as a social good is consistent with the moral terms used by Stallman, founder of the Free Software Foundation: "I knew that at the end of my career, I would look back on years of building walls to divide people, and feel I had spent my life making the world a worse place" [45]. The identification of business objectives with social mission was observed in Catalyst IT, Gnutiken, Open Source Telecom, Understanding Limited and We Go To 12.

This contrasts with the socially-minded co-founder of the anonymous OSS company, who expressed his contributions in terms of earning enough money to donate to worthy causes.

We wanted to write extremely high quality software that would essentially earn a decent living for the two of us and give us something left over to invest in primary education for girls in [a country]. We wanted to invest about ten percent of our profits in that and have, and be able to pay ourselves enough to keep everything going. $\left(\mathrm{Ob}_{i 1}\right)$

\subsection{Definition of Success Includes Social Mission}

Success in a social entrepreneurship is in part measured by mission and impact [33, 43]. The Success theme in Table 4 shows the presence of mentions of measures of success. Social aims directly related to FLOSS were present in the codes free software required and purpose, which were found in the anonymous company, Catalyst IT, Open Source Telecom, Understanding Limited and We Go To 12. 
So I definitely think it would be a failure of the company if we changed business model to a proprietary one. $\left(\mathrm{Ul}_{i 1}\right)$

But you know, as a company we've also defined our goal and as we move toward that goal that's a measure of success as well. And that goal was, as I've mentioned, is that free and open-source software is the preferred technology for New Zealand, so anything we do toward that goal helps, and the fact that if the company is successful then it does two things. It's a demonstration that free software is appropriate and can be successful in the business world. $\left(\mathrm{Ca}_{i 1}\right)$

\subsection{Summary}

All three elements of social entrepreneurship are present in two of the FOSS identified companies, Understanding Limited and We Go To 12. Gnutiken, Catalyst IT and Open Source Telecom, the other three companies founded by people with a FOSS philosophy, had each had two of the three characteristics of social entrepreneurship. Of the companies not affiliated with FOSS, the anonymous company met one of the criteria of a social entrepreneurship and Conecta did not fit any.

\section{LIMITATIONS}

Like any other research method, the case study has limitations. It permits the generalization of theoretical propositions but not to a population $[7,54]$.

Case studies are strengthened through data triangulation $[20,54]$. Only a handful of public documents were available and no internal documents could be obtained. This was compensated for by the number and breadth of cases, and through comparison with existing FLOSS literature [50].

In this research, respondents were self-selected, so it is likely that only individuals with strong feelings about FLOSS participated. However, as this study was specifically focused on companies whose founders identified with FOSS, the strong sense of identity is desirable. If the people who did not identify with FOSS were likewise motivated to participate by strong feelings about FLOSS, it strengthens the findings by reducing the unstudied differences between the cases.

When performing qualitative data analysis there is a risk that the researcher's background will influence the data collection and interpretation [36] or that interaction between the researcher and subjects leads to the development of data [22]. The research and participants had limited interaction and were already familiar with the FLOSS concepts described in this research, reducing the chance that either the data or interpretations were inaccurate. The results of the research were also shown to participants to ensure the accuracy of the interpretation.

\section{CONCLUSIONS}

There appear to be differences between companies founded by people who identify with free software and companies founded by people who identify with open source. Businesses founded by people who believe in the FOSS philoso- phy share some characteristics with social entrepreneurships, but it would be premature to conclude that FOSS businesses are always social entrepreneurships. Other factors, most notably size, appear to be related to attitudes toward financial as compared to social measures of success.

This paper proposes the following theory:

Small companies founded by people who identify with the free/libre software philosophy largely have the three defining characteristics of social entrepreneurship, namely:

- Social benefit is prioritized over wealth creation,

- The social mission is not incidental but is furthered through the company's for-profit activities, and

- The company's success is in part defined by the success of its social mission.

Larger FOSS firms may contain some elements of social entrepreneurships, while companies which use FLOSS methods but do not identify with FOSS do not significantly overlap with social entrepreneurships, even when there is a strong interest in social aims.

Entrepreneurs who take an ethical stance on FOSS and observe the three aspects of a social entrepreneurship in their own companies may benefit from examining advice to social entrepreneurships to address specific concerns such as how to balance financial needs with social goals.

\section{ACKNOWLEDGMENTS}

The author would like to thank the company founders who participated in the research and Rita Walczuch and Mark Vluggen, who provided feedback at an early stage.

\section{References}

[1] Rishab Aiyer Ghosh et al. Free/Libre and Open Source Software: Survey and Study. Final Report. Oct 2002.

[2] James Austin, Howard Stevenson, and Jane Wei-Skillem. "Social and Commercial Entrepreneurship: Same, Different, or Both?" In: Entrepreneurship Theory and Practice (Jan 2006), pp. 1-22.

[3] James Bessen. "Open Source Software: Free Provision of Complex Public Goods". In: The Economics of Open Source Software Development. Ed. by Jürgen Bitzer and Philipp J.H. Schröder. Amsterdam, The Netherlands: Elsevier, 2006. Chap. 3, pp. 57-82.

[4] Edwin Blake and William Tucker. Socially Aware Software Engineering for the Developing World. Ed. by Paul Cunningham and Miriam Cunningham. Information Society Technologies - Africa 2006. Pretoria, South Africa. 2006.

[5] Andrea Bonaccorsi and Christina Rossi. "Contributing to the common pool resources in Open Source software. A comparison between individuals and firms". In: (Aug. 2003).

[6] Patrick Carmichael and Leslie Honour. "Open Source as appropriate technology for global education". In: International Journal of Educational Development 22 (2002), pp. 47-53. 
[7] A.L.M. Cavaye. "Case study research: a multi-faceted research approach for IS". In: Information Systems Journal 6.3 (1996), pp. 227-242.

[8] Mathieu-Claude Chaboud. "Pirates never sail alone: exploring the mechanics of social entrepreneurship involved in software piracy". In: International Journal of Entrepreneurship and Small Business 22.4 (2014), pp. 519-536.

[9] Albert Hyunbae Cho. "Politics, values and social entrepreneurship: a critical appraisal". In: Social entrepreneurship 280 (2006).

[10] S. Chopra and S. Dexter. A Comparative Ethical Assessment of Free Software Licensing Schemes. Accessed Aug 8, 2010. URL: http://www.sci.brooklyn. cuny . edu/ sdexter/copyleft_ethics.html.

[11] Catherine H. Clark and Selen Ucak. For-Profit Social Entrepreneur Report: Balancing Market Values. Social Enterprise Program. Mar 2006.

[12] Juliet M Corbin and Anselm Strauss. "Grounded theory research: Procedures, canons, and evaluative criteria". In: Qualitative sociology 13.1 (1990), pp. 3-21.

[13] Carlo Daffara. Economic Free Software perspectives. Accessed Jun 12, 2010. May 4, 2009. URL: http:// carlodaffara. conecta $\cdot$ it $/ \mathrm{p}=216$.

[14] Kathleen M. Eisenhardt. "Building Theories from Case Study Research". In: Academy of Management Review 14.4 (1989), pp. 532-550.

[15] Kathleen M. Eisenhardt and Melissa Graebner. "Theory Building from Cases: Opportunities and Challenges". In: Academy of Management Journal 50.1 (2007), pp. 2532 .

[16] Joseph Feller and Brian Fitzgerald. Understanding Open Source Software Development. B: Addison Wesley, 2002.

[17] Bent Flyvbjerg. "Five Misunderstandings About CaseStudy Research". In: Qualitative Inquiry 12.2 (2006), pp. 219-245.

[18] Free Software Foundation, ed. Accessed Jan 15, 2008. URL: http://www.fsf .org/licensing/essays/freesw.html.

[19] Francis Fukuyama. "Social capital, civil society and development". In: Third World Quarterly 22.1 (2001), pp. $7-20$.

[20] Lisa A Guion, David C Diehl, and Debra McDonald. Triangulation: Establishing the validity of qualitative studies. 2011.

[21] Alexander Hars and Shaosong Ou. Working for Free? - Motivations of Participating in Open Source Projects. Proceedings of the 34th Hawaii International Conference on System Sciences. 2001. URL: http://citeseerx ist . psu . edu/viewdoc/download?doi=10.1.1.105. 8675\&rep $=r e p 1 \&$ type $=p d f$.

[22] Heinz K. Klein and Michael D. Myers. "A Set of Principles for Conducting and Evaluating Interpretive Field Studies in Information Systems". In: MIS Quarterly 23.1 (Mar 1999), pp. 67-93.

[23] Bradley M. Kuhn and Richard Stallman. Freedom or Power? GNU Operating System. Accessed Aug 1, 2010. Jul 5, 2010. URL: http://www.gnu.org/philosophy/ freedom-or-power.html.
[24] Karim R Lakhani and Robert G Wolf. "Why hackers do what they do: Understanding motivation and effort in free/open source software projects". In: Perspectives on Free and Open Source Software. Ed. by Joseph Feller et al. C: The MIT Press, 2005, pp. 3-22.

[25] Charles Leadbeater. What are the future scenarios for social enterprise. Social Enterprise Think Pieces: Outline Proposals. Aug 2007.

[26] Josh Lerner and Jean Tirole. "Some simple economics of open source". In: The Journal of Industrial Economics 50.2 (Jun 2002), pp. 197-234.

[27] Ann Chih Lin. "Bridging Positivist and Interpretivist Approaches to Qualitative Methods". In: Policy Studies Journal 26.1 (1998), pp. 162-180.

[28] Alasdair MacIntyre. After Virtue: A Study in Moral Theory. Third Edition. N: University of Notre Dame Press, 1981/2007.

[29] Johanna Mair and Ignasi Marí. "Social entrepreneurship research: A source of explanation, prediction, and delight". In: Journal of World Business 41 (2006), pp. 3644.

[30] Roger L. Martin and Sally Osberg. "Social Entrepreneurship: The Case for Definition". In: Stanford Social Innovation Review (Spr 2007), pp. 28-39.

[31] Christopher May. "Escaping the TRIPs Trap: The Political Economy of Free and Open Source Software in Africa". In: Political Studies 54.1 (Mar 2006), pp. 123146.

[32] Glyn Moody. Why No Billion-Dollar Open Source Companies? Accessed Jun 12, 2010. Jun 11, 2010. URL: http: //www . computerworlduk . com/toolbox/opensource/blogs/index. cfm?entryid=3010\&blogid=14.

[33] Heidi Neck, Candida Brush, and Elaine Allen. "The landscape of social entrepreneurship". In: Business Horizons 52 (2009), pp. 13-19.

[34] Stephen O'Grady. What is an "Open Source Company?" The Billion Dollar Question. Accessed June 12, 2010. Feb 25, 2009. URL: http://redmonk.com/ sogrady/2009/02/25/opensource_billions/.

[35] Caroline Parkinson and Carole Howorth. "The language of social entrepreneurs". In: Entrepreneurship 8 Regional Development 20 (May 2008), pp. 285-309.

[36] Michael Quinn Patton. "Enhancing the Quality and Credibility of Qualitative Analysis". In: Health Services Research 34.5 (Dec 1999), pp. 1189-1208.

[37] Bjørn Reese and Daniel Stenberg. Working Without Copyleft. Accessed Aug 8, 2010. Dec 2001. URL: http: //daniel.haxx.se/transition.html.

[38] Dave Roberts and Christine Woods. "Changing the world on a shoestring: The concept of social entrepreneurship". In: University of Auckland Business Review (2005), pp. $45-51$.

[39] Cristina Rossi and Andrea Bonaccorsi. "Intrinsic Motivations and Profit-Oriented Firms in Open Source Software: Do Firms Practise What they Preach?" In: The Economics of Open Source Software Development. Ed. by Jürgen Bitzer and Philipp J.H. Schröder. Amsterdam, The Netherlands: Elsevier, 2006. Chap. 4, pp. 83-110. 
[40] Maria Alessandra Rossi. "Decoding the Free/Open Source Software Puzzle". In: The Economics of Open Source Software Development. Ed. by Jürgen Bitzer and Philipp J.H. Schröder. Amsterdam, The Netherlands: Elsevier, 2006. Chap. 2, pp. 15-56.

[41] Christian Seelos and Johanna Mair. "Social entrepreneurship: Creating new business models to serve the poor". In: Business Horizons 48.3 (May/Jun 2005), pp. 241246.

[42] Sonali K Shah. "Motivation, governance, and the viability of hybrid forms in open source software development". In: Management Science 52.7 (2006), pp. 10001014.

[43] Moshe Sharir and Miri Lerner. "Gauging the success of social ventures initiated by individual social entrepreneurs". In: Journal of World Business 41 (2006), pp. 6-20.

[44] Kimberly D. Simon. "The value of open standards and open-source software in government environments". In: IBM Systems Journal 44.2 (2005), pp. 227-238.

[45] Richard Stallman. Free Software, Free Society: Selected Essays of Richard M. Stallman. Ed. by Joshua Gay. B: GNU Press, 2002.

[46] Richard Stallman. "The GNU Operating System and the Free Software Movement". In: ed. by Chris DiBona, Sam Ockman, and Mark Stone. S: O'Reilly \& Associates, Inc., 1999, pp. 53-70.

[47] Richard Stallman, Rishab Aiyer Ghosh, and Ruediger Glott. The Stallman-Ghosh-Glott mail exchange on the FLOSS survey. Accessed June 19, 2010. 2002. URL: http://flossproject.org/floss1/stallman.html.

[48] Mukesh Sud, Craig V. VanSandt, and Amanda M. Baugous. "Social Entrepreneurship: The Role of Institutions". In: Journal of Business Ethics 85 (2008), pp. 201-216.

[49] Gillian Sullivan Mort, Jay Weerawardena, and Kashonia Carnegie. "Social entrepreneurship: Towards conceptualisation". In: International Journal of Nonprofit and Voluntary Sector Marketing 8.1 (2003), pp. 76-88.

[50] David R. Thomas. "A General Inductive Approach for Analyzing Qualitative Evaluation Data". In: American Journal of Evaluation 27.2 (Jun 2006), pp. 237-246.

[51] Georg Von Krogh, Sebastian Spaeth, and Karim R Lakhani. "Community, joining, and specialization in open source software innovation: a case study". In: Research Policy 32.7 (2003), pp. 1217-1241.

[52] Elizabeth Walker and Alan Brown. "What Success Factors are Important to Small Business Owners?" In: International Small Business Journal 22 (2004), pp. 577-594.

[53] Thorsten Wichmann. FLOSS Final Report - Part 2: Firms' Open Source Activities: Motivations and Policy Implications. FLOSS - Free/Libre Open Source Software: Survey and Study. Jul 2002.

[54] Robert K Yin. Case study research: Design and methods. Sage publications, 2013.

[55] Shaker A. Zahra et al. "A typology of social entrepreneurs: Motives, search processes and ethical challenges". In: Journal of Business Venturing (2008). 